\title{
Relationships of exercise with frailty, depression, and cognitive function in older women
}

\author{
Bog Ja Jeoung* \\ Department of Exercise Rehabilitation \& Welfare, College of Health Science, Gachon University, Incheon, Korea
}

The purpose of the present study was to provide basic data to identify which types of exercise promote health of older adults. To this end, this study investigated how exercise affects frailty, depression, and cognitive functions in older adults. Frailty, depression, and cognitive function assessed in the exercise participants, 164 older adult women. Results revealed that participants' frailty and depression varied according to exercise participation time and frequency. In particular, dancing was more effective than other types of exercise in reducing frailty and de- pression. Exercise duration and frequency did not influence cognitive function, but results indicated that table tennis exerted a greater influence on cognitive function than other types of exercise did. In addition, cognitive function differed according to the degree of frailty participants displayed.

Keywords: Aging, exercise, Frailty, Depression, Cognitive function

\section{INTRODUCTION}

Developments in medicine have extended the average lifespan. However, in South Korea, the size of the older adult population is increasing rapidly as years pass, and the country also has a low birth rate. South Korea had already become an aging society by the year 2000, when the proportion of the older adult population (age 65 and above) reached $7 \%$ of the overall population. By 2010, the older adult population had reached 5.45 million people, constituting $11 \%$ of the total South Korean population. It is predicted that the older adult population will increase to at least $14 \%$ by 2018 , with South Korea thereby becoming an aged society (Kim and Oh, 2014). The increase observed in the older adult population in South Korea has been more dramatic than that of advanced countries, including Japan, with a population traditionally known for its longevity. South Korea, less prepared to confront the realities of an aged society, is facing severe socioeconomic and medical issues. Consequently, a comprehensive health promotion plan to raise the healthy life expectancy of the older adult population is necessary.
The majority of older adults are afflicted with at least two or more of chronic degenerative diseases simultaneously, resulting in a rapid increase in health and medical expenditure. Furthermore, older adults who have difficulties managing an autonomous daily life, including those with dementia, are in need of help from guardians or caretakers, which generates a significant loss to society and the national economy. Over $90 \%$ of older adults in Korea have been shown to be afflicted with at least one type of chronic disease. Among them, the most prevalent disease was rheumatism, followed by hypertension and neuralgia. Furthermore, $55.6 \%$ of older adults perceived their health as poor (Park et al., 2014). Such statistics indicate that despite increased life expectancy, older adults do not enjoy their later years in good health. Instead, older adult people lived their longer lives in pain, suffering from numerous disease-associated health problems.

Deteriorating physiological and psychological functions, as well as diminishing social capacities, transform many older adults into frail dependents who rely on others to perform everyday tasks. Such frail older adults neglect to address their illnesses because of their difficulties in performing everyday tasks. This leads to fur-
${ }^{*}$ Corresponding author: Bog Ja Jeoung

Department of Exercise Rehabilitation \& Welfare, College of Health Science,

191 Hambakmoeiro, Yeonsu-gu, Incheon 461-701, Korea

Tel: +82-32-820-4766, Fax: +82-32-820-4049, E-mail: bogja05@gachon.ac.kr

Received: July 2, 2014 / Accepted: October 15, 2014
This is an Open Access article distributed under the terms of the Creative Commons Attribution Non-Commercial License (http://creativecommons.org/licenses/by-nc/3.0/) which permits unrestricted non-commercial use, distribution, and reproduction in any medium, provided the original work is properly cited. 
ther deterioration of their health and prolongs the convalescence period for any disease they suffer and they continue to age with diminishing quality of life. It is necessary to establish measures to prevent this situation from occurring in frail older adults, increase their average life expectancies, and help them to live healthy lives in their later years (Bruce, 1989; Chou et al., 2012; Lee et al., 2013; Lee et al., 2013; Park et al., 2013).

"Frail elderly" is defined as older adults in a transitional phase in which they are not officially suffering from disabilities but are distinguished from healthy older adults without disease or decrepitude (Cho, 2013). Frail older adults develop disabilities in performing daily tasks, which increases their risk of injury. As injuries can lead to full-fledged disabilities, studies on frail older adults are vital as a preventive measure. In previous studies on the prevention of frailty in the older adult population, findings on physical activity, exercise, and physical strength were presented. Previous studies all corroborate findings that regular exercise and physical strength contribute to decreasing social costs. Thus, numerous studies have examined physical strength, physical activity, and exercise; factors associated with the health of older adults; and means of delaying senescence (Everett and Catherine, 1994; Kang, 2007; Rikli and Jones, 1997). Although propose that regular exercise is crucial for maintaining health in older adults in such studies. Despite these findings, only $9.9 \%-22.6 \%$ of Korean older adults have been found to engage in regular exercise (Kim and Oh, 2014). This rate may be low because of a lack of education regarding exercise methods and low levels of motivation. Therefore, this study sought to present basic data for developing and implementing exercise-based interventions might better convey your intention for healthy older adults, investigating differences in the impact on frailty and cognitive functioning according to exercise type.

\section{MATERIALS AND METHODS}

\section{Participants}

The participants were recruited from the Welfare Center for Older People in Incheon city. One hundred sixty-four women aged $60 \mathrm{yr}$ and older who had participated in the institution's exercise and education program and filled out the consent form to participate in the present study were ultimately selected as participants. Once the participants were selected, their exercise participation, frailty assessment scores, and cognitive function were recorded. The average age of the participants was $73.13 \pm 6.02$ (60-80 aged), and their general characteristics are shown in Table 1.

\section{Instruments}

\section{Frailty assessment}

The frailty assessment is a basic measurement tool originally developed by the Ministry of Health, Labour and Welfare of Japan to select subjects for preventative health care. It was revised and supplemented by Korea Institute Health and Social Affairs to accommodate the Korean language (Park et al., 2012). It measures the frailty of older adult participants and consists of 5 lifestyle function questions, 5 physiological motor function questions, 2 nutrition status questions, 3 oral health function questions, 2 social capacity questions, and 3 cognitive function questions (total of 20 questions). Combined with 5 questions related to depression prevention and support, the tool is composed of 25 questions and 7 sub-categories.

\begin{tabular}{|c|c|c|c|}
\hline & Participation & Exercise duration (min/wk) & Exercise type \\
\hline \multirow[t]{5}{*}{ Exercise } & y: $126(76.8 \%)$ & $<90: 11(6.7 \%)$ & Dancing: $31(18.9 \%)$ \\
\hline & & $90-240: 41(25 \%)$ & Walking: 40 (24.4\%) \\
\hline & & 240 - 450: $47(28.7 \%)$ & Gymnastics: 26 (15.9\%) \\
\hline & & $>450: 27(16.5 \%)$ & Resistance training: $17(10.4 \%)$ \\
\hline & n: $38(23.2 \%)$ & & \\
\hline \multirow[t]{5}{*}{ Education } & Uneducated & $16(9.7 \%)$ & \\
\hline & Elementary & $39(23.8 \%)$ & \\
\hline & Middle school & $28(17.1 \%)$ & \\
\hline & High school & $61(37.2 \%)$ & \\
\hline & Graduation & $20(12.2 \%)$ & \\
\hline \multirow[t]{3}{*}{ Income } & y: $81(49.4 \%)$ & $<甘 1$ million: 50 (30.5\%) & \\
\hline & & $>$ >1 million: 31 (18.9\%) & \\
\hline & n: $83(50.6 \%)$ & & \\
\hline
\end{tabular}




\section{Cognitive function (short form of the MMSE-K: memory and recall, 3-word recall)}

The cognitive function evaluation tool used in the present study consists of a Korean adaptation, developed by Cho et al. (2013), of "a brief version of the MMSE, a measure of cognitive functioning in elderly adults in the West. This tool assesses memory recall through a 3-word recall task; it has confirmed internal consistency and a sensitivity of $72.7 \%$."

\section{Procedure}

The participants were asked to write down the type, duration, frequency, and duration of any exercise that they had engaged in during the previous week. The amount of exercise was based on total amounts of exercise participation time during a single week and measured by calculating the type, duration, and frequency of exercise in which participants had engaged consistently for at least 3 months.

\section{Statistical analysis}

The statistical analysis was performed using SPSS for Windows, version 21 (IBM SPSS Inc., Chicago, IL, USA). Data were analyzed using linear regression and descriptive statistics. The significance threshold was set at 0.05 .

\section{RESULTS}

Analysis of the correlations between exercise method and frailty and depression showed that frailty and depression were related to exercise time and participation frequency in elderly women (Tables 2, 3). In other words, as exercise duration increased, frailty and depression scores also increased. Furthermore, the frailty and

Table 2. Frailty and depression according to exercise duration

\begin{tabular}{lccccc}
\hline & \multicolumn{5}{c}{ Exercise duration per week } \\
\cline { 2 - 6 } & $\mathrm{b}$ & $\mathrm{B}$ & $\mathrm{R}^{2}$ & $\mathrm{t}$ & $P$ \\
\hline Frailty & 18.89 & 0.166 & 0.028 & 2.144 & $0.034^{*}$ \\
Frailty and depression & 16.25 & 0.183 & 0.034 & 2.37 & $0.019^{*}$ \\
\hline
\end{tabular}

${ }^{*} P<0.05$.

Table 3. Frailty and depression according to exercise frequency

\begin{tabular}{lccccc}
\hline & \multicolumn{5}{c}{ Exercise frequency per week } \\
\cline { 2 - 6 } & $\mathrm{b}$ & $\mathrm{B}$ & $\mathrm{R}^{2}$ & $\mathrm{t}$ & $P$ \\
\hline Frailty & 0.133 & 0.189 & 0.036 & 2.45 & $0.015^{*}$ \\
Frailty and depression & 0.109 & 0.199 & 0.039 & 2.58 & $0.011^{*}$ \\
\hline
\end{tabular}

${ }^{*} P<0.05$. depression scores also increased with exercise frequency $(P<0.05)$. Frailty or depression scores did not significantly differ across different types of exercise. However, frailty scores were higher for dancing and walking than the other types of exercise. Although the short-form MMSE-K scores did not differ with respect to exercise duration or frequency, they did differ according to exercise type. The mean short-form MMSE-K score was highest in older women who played table tennis, followed by those who participated in dancing. Gymnastics had the lowest frailty and depression scores. Analysis of the correlation between frailty and depression and short form MMSE-K scores showed that frailty and depression influenced short-form MMSE-K scores (Table 4).

\section{DISCUSSION}

Aging decreases not only physiological but also psychological and social functions. However, according to several previous studies, regular exercise and physical activity can prevent various components of age-related functional decline (Park et al., 2012). Regular exercise prevents the degeneration of physical functioning and contributes to improving psychological functioning. To promote the health of older adults, appropriate and regular exercise is necessary. The American College of Sports Medicine (ACSM, 2013) has a general recommendation of for $30 \mathrm{~min}$ of exercise per day, 3-5 times per week for frail older adults. With regard to suitable types of exercise, the ACSM recommends aerobic exercise, such as walking, hiking, or strength training, and mental and physical exercise, such as tai chi or balancing exercises. Additionally, Yun et al. (2013) reported that it is more effective to engage in low-intensity exercise for a long period than it is to engage in high-intensity exercise. Conversely, Kim and Kim (2003) reported that high-intensity exercise is effective; therefore, there may be differences in exercise effects for older women depending on the intensity of the exercise. In addition, Han et al. (2007) reported that an effective schedule of exercise participation duration and frequency was that of 3 times per week for 50 min each time. In contrast, Kim and Lee (2009) reported that exercise is effective only if performed 5 times per week for an hour each time, which

Table 4. Frailty and depression according to short-form MMSE-K score

\begin{tabular}{lccccc} 
& \multicolumn{5}{c}{ Short-form MMSE-K } \\
\cline { 2 - 6 } & $\mathrm{b}$ & $\mathrm{B}$ & $\mathrm{R}^{2}$ & $\mathrm{t}$ & $P$ \\
\hline Frailty & 0.271 & 0.244 & 0.060 & 3.19 & $0.002^{* *}$ \\
Frailty and depression & 0.287 & 0.201 & 0.040 & 2.60 & $0.010^{* *}$ \\
\hline
\end{tabular}

${ }^{* *} P<0.01$. 
shows that there is disagreement regarding effective exercise duration and frequency. Previous studies, such as those conducted by Rejeski et al. (2005) and Kim and Kim (2003), have reported that 8 weeks of short-term exercise participation twice weekly did not lead to improvements in muscular strength or physical fitness.

Summarizing existing evidences on exercise for frail older adults, it can be said that exercising for $60 \mathrm{~min}, 5$ times a week, is more effective than exercising for $30 \mathrm{~min}, 2-3$ times a week. The findings of this study also showed that participating in exercise for $60 \mathrm{~min}$ per day, 5 times a week, was effective in preventing and improving the physical conditions of frail older adults. This supports the study by Han et al. (2007), suggesting that frail older adults' physical condition improved when they participated in exercise for a relatively long period of time (at least 12 weeks, 5 sessions weekly, for $60 \mathrm{~min}$ per session).

This study sought to investigate correlations between exercise participation in frail older women and depression and cognitive function. To this end, women aged $60 \mathrm{yr}$ and older who were participating in programs provided by senior welfare centers were selected as participants, and their Frailty, depression, and short-form MMSE-K (memory recall; 3-word recall) scores were assessed. The duration required for exercise to exert a positive influence on frailty, depression, and cognitive function in older women was at least 60 min per session, with a frequency of 5 times a week. Regarding suitable exercise types, dancing exerted a positive influence on frailty and depression scores. Further, exercises that required the use of tools, such as table tennis, appeared to have a positive influence on the improvement of cognitive function in older women. Although the present study found that some exercise types did not exert a positive influence on cognitive function, regular exercise was found to be important in improving short-form MMSE-K scores. Furthermore, because frail older adults are vulnerable to memory defects, regular exercise is very important in preventing frailty.

\section{CONFLICT OF INTEREST}

No potential conflict of interest relevant to this article was reported.

\section{REFERENCES}

ACSM. American college sports medicine exercise for older adults.

Boomerng Books 2013.

Bruce, CJ. Physical activity, exercise and physical fitness: Definitions and distinctions for health-related research. Public Health Report 1989; 100:126-131.

Cho B, Son KY, Oh B, Kim SJ, Kwon IS, Park BJ, Woo DS, Yoon JL, Won CW, Hwang HS, Ga H. Development and validity and reliability of Korean comprehensive assessment tools for geriatric ambulatory care. J Korea Geratr Soc 2013;17:18-27.

Chou C, Hwang C, Wu Y. Effect of exercise on physical function, daily living activities, and quality of life in the frail older adults: A meta-analysis. Arch Phys Med Rehabil 2012;93:237-244.

Everett JM, Catherine EM. A short physical performance battery assessing lower extremity function: association with self-reported disability and prediction of mortality and nursing home admission, J Gerontol 1994;49:85-94.

Han Y, Choi C, Lee P. Development and effect of the customized health gymnastics program for the frail old. Korean J Physic Edu 2007;46:595606.

Kang S. Comparison of aging threshold and aging coefficient in health related physical fitness on Korean and Japanese. Korean J Physic Edu 2007;46:723-736.

Kim S, Oh H. The relationship among social support, self-regulation and depression for the elderly participating in physical activity. J Sport Leisure Stud 2014;57:673 683.

Kim YJ, Lee JH. The effects of a physical activity promotion programs with telecoaching negotiation on physical fitness and quality of life in the frail elderly. J Korea Acad Community Health Nurs 2009;20:391-402

Kim H, Kim N. The effect of rubber-band exercise on daily living fitness among. Korean J Physic Edu 2003;42:649-655.

Lee E, Lee K, Kozyreva O. The effects of complex exercise rehabilitation program on body composition, blood pressure, blood sugar, and vessel elasticity in elderly women with obesity. J Exerc Rehabil 2013;9:514-519.

Lee B, Kim J, Oh D. The effects of combined exercise intervention on body composition and physical fitness in elderly females at a nursing home. J Exerc Rehabil 2013;9:298-303.

Park C, Elavsky S, Koo K. Factors influencing physical activity in older adults. J Exerc Rehabi 2014;10:45-52.

Park Y, Lee K, Kim T, Jeon M, Kim D, Kim J. The effects of exercise in the frail elderly. J Korea Acad Community Health Nurs 2012;23:191-101.

Rejeski WJ, Katula J, Rejeski A. Rowley J, Sipe M. Strength training in older adults; does desire determine confidence? J Gerontol B Psychol Sci Soc Sci 2005;60:335-337

Rikli E, Jones CJ. Assessing physical performance in independent older adults: Issues anf guide lines. J Aging Physic Activity 1997;5:244-261.

Yun H, Kim E, Suh S, Kim M, Kim H. Diabetes reduces the cognitive function with the decrease of the visual perception and visual motor integration in male older adults J Exerc Rehabil 2013;9:470-476. 